\title{
Application of High Pressure Homogenization to Improve Stability and Decrease Droplet Size in Emulsion-Flavor Systems
}

\author{
Ocampo-Salinas I. O., Tellez-Medina D. I., Jimenez-Martinez C., Davila-Ortiz G. *
}

\begin{abstract}
Departamento de Ingeniería Bioquímica, Escuela Nacional de Ciencias Biológicas, Instituto Politécnico Nacional, Unidad Profesional Adolfo López Mateos, Av. Wilfrido Massieu Esq. Cda. Miguel Stampa S/N, C.P.07738 Delegación Gustavo A. Madero, Ciudad de México, México
\end{abstract}

\begin{abstract}
Flavor is a mixture of organic compounds and is a quality parameter for food acceptability. During processing and storage, the concentration of flavor in foods could be diminished because of its volatility, causing a decrease in its intensity and food quality. Emulsions can mitigate flavor release upon food consumption; however, emulsions are thermodynamically unstable and are prone to develop particle size growth that contribute to instability; because of that, given their high physical stability, there is a deep interest in nanoemulsions to incorporate flavors in foods and beverages. Using different valves systems such as radial diffusers, counter jet dispersers and orifice valves, it is possible to apply high pressures for homogenization of flavor emulsion systems in order to reduce droplet size and to improve stability. This review compiles and analyzes works related to the application of each homogenization system mentioned above in terms of the physicochemical and engineering principles implicated.
\end{abstract}

Keywords - Cavitation, high pressure homogenization, homogenization valves, nanoemulsions, volatile compounds

\section{INTRODUCTION}

Sensory properties are important factors for the acceptability of any food; particularly, flavor is an important element in any food formula since flavor could be an expensive and delicate ingredient $(1,2)$. Manufacturing and storage processes as well as packaging materials and ingredients in food products often generate modifications in overall flavor by reducing the intensity of aroma compounds or producing off-flavor components. Many factors linked to aroma affect in general the quality of foods; for instance, the presence of proteins, polysaccharides or lipids (even trace) reduces the volatility of an aroma compound with respect to its volatility in pure water $(3,4)$.

Interactions of water with aroma compounds (or with any other solute) can be estimated by either the Raoult's or
Henry's laws. Interactions between a solute and a solvent are represented by the activity coefficient ( $\gamma \mathrm{i})$ : the higher the $\gamma \mathrm{i}$, the greater the difference between solute and solvent (or solution constituents) nature. Thus, the deviation from ideality ( $\gamma \mathrm{i}=1$ ) becomes larger $(5)$.

The affinity of an aroma compound for the different phases (food products are emulsified, gelified, or both) of a system affects its availability in the vapor phase; besides, perception of many flavor characteristics depends greatly on the nature of the food matrix components such as proteins, carbohydrates and lipids that are well known to interact with flavor compounds. The physicochemical interactions that occur between aroma compounds and other constituents of the food matrix play an important role in the retention of volatile substances during food processing $(3,6)$.

Flavor release is defined as a transport process of the flavor compound from the matrix to the vapor phase; thus, the decrease in food quality may be related to the loss of small-molecule aroma compounds and this causes a reduction of flavor intensity and change in the typical food flavor $(7,8)$. A good knowledge of the physicochemical interactions occurring between flavor compounds and other major food components is required for the control of food flavoring because the composition of the food matrix and its variations significantly contribute to different interactions between the flavor compounds with other food components, which consequently influence the equilibrium headspace concentration of flavor compounds (8).

Thermodynamics, represented by the volatility of the flavor in the food, and kinetics, characterized by the resistance to mass transfer from product to air, define the release of volatile flavor compounds from products, but only the latter is affected by the matrix texture and this becomes apparent only under dynamic (non-equilibrium) conditions. Under strongly mass transfer controlled conditions, flavor retention and release is determined by diffusion. In liquid and semi-solid systems the diffusion 
rates of flavor compounds do not differ much; thus, the release rates tend also to become similar under mass transfer controlled conditions (9). The transfer rate of an aroma compound at the lipid-water interface mainly depends on its affinity for each phase involved (3).

Due to its solvent properties, type of fat and its concentration strongly influences the release of flavor compounds and their perception during consumption, modifies the physical properties of foods and influences the textural changes of the food product $(10,11)$.

Fat has a significant effect on the partition of volatile compounds between the food and the air phases with lipophilic aroma compounds being the most affected. If fat content is decreased, the amount of lipophilic aromas in the flavor formulation also needs to be diminished in order to maintain the same profile of aroma released from the product. Since it is now established that flavor perception occurs through a cross-modal system (i.e., the sensations of aroma, taste, and texture interact to constitute a particular perception), it is obvious that changing one modality, such as viscosity, can affect the overall perceived flavor. It is generally assumed that increasing viscosity through the addition of thickening agents, results in a decrease in flavor and taste intensity. However, the decrease seems to be dependent on thickener type $(11,12)$.

Volatile compounds and matrix characteristics must be taken into account to explain the transfer process. In particular, physicochemical characteristics of volatile compounds influence their release: molecular shape, size and weight of the aroma compound affect its diffusivity, whereas solubility is influenced by the compound nature, polarity, and ability to condense. In order to prevent flavor changes during food conservation, different strategies could be used (7).

Given the above, there is considerable interest within the food industry in the development of food-grade delivery systems to incorporate lipophilic functional components, such as flavors, into foods and beverages. One of the most important aspects of flavor emulsions is how they mitigate flavor constituent release properties upon consumption $(13,14)$; for instance, the flavor components in citrus oil emulsions are prone to physical deterioration leading to decrease in product quality and shorter shelf life. Therefore, formation of chemically and physically stable oil emulsions for use in foods and beverages would be a major advantage for the food industry (15). A number of different colloid-based delivery systems have been shown to be particularly suitable for this purpose, including microemulsions, nanoemulsions, and emulsions. These colloidal systems differ in their composition, physicochemical properties, and thermodynamic stability, which lead to differences in their functional performances. Colloidal delivery systems can be entirely generated from food-grade ingredients using simple processing operations (14).

\section{EMULSIONS, MICROEMULSIONS AND NANOEMULSIONS}

The definition of 'emulsion' by the International Union of Pure and Applied Chemistry (IUPAC) states: "In an emulsion, liquid droplets and/or liquid crystals are dispersed into a liquid" (16).

Food emulsions are subjected to the same principles than other emulsion systems; they contain droplets with mean radii ranging $100 \mathrm{~nm}-100 \mu \mathrm{m}$ and, as a consequence, tend to be optically turbid or opaque since the constituent droplets have similar size to visible light wavelengths so that the former strongly scatter light. Food emulsions are complex systems, and must contain only ingredients that are acceptable for human consumption; besides, water and oil may contain proteins, polysaccharides, low molecular weight surfactants, salts, sugars, alcohol, antimicrobial agents, dyes or flavorings. Oil-in-water (o/w) emulsions (cream, dressings, etc.) are typically fluid and may contain a (partially) crystalline oil phase whereas food-related water-in-oil (w/o) emulsions (butter, margarine, etc.) are typically solid-like. Traditionally, oilin-water $(\mathrm{o} / \mathrm{w})$ emulsions are produced by homogenizing oil and aqueous phases together so that one of the phases gets dispersed in the other by forming small droplets (14, 17-20).

Technologically, due to their droplet size, one of the greatest complications is that emulsions are thermodynamically unstable because of the energy required to increase the surface area between oil and aqueous phases and, therefore, an increase in free energy; hence, emulsions tend to separate into their constituent phases with time or tend to break during certain processing operations (heat treatment, mechanical deformation, freezing, etc.) $(14,21,22)$.

In physicochemical terms, particular features of emulsions are the presence and nature of the aqueous phase-lipid phase interface, the surface area of such interface, and the nature and amount of the surface active agent adsorbed at this oil-water interface that is required to stabilize such emulsion $(1,20)$.

Five main mechanisms contribute to emulsion instability:

- Creaming (or sedimentation); is due to differences in density between the two phases under the influence of gravity which leads to phase separation.

- Flocculation; is best described as the aggregation of particles, that retain their structural integrity, due to weak attractive forces between colloids, 
as well-described by the Derjaguin, Landau, Verwey and Overbeek (DLVO).

- (Partial) coalescence; two colliding droplets will form a single larger droplet. May be complete when the droplets are liquid or partial if the droplets contain crystalline matter.

- $\quad$ Phase inversion; partial coalescence can lead to phase inversion where $\mathrm{O} / \mathrm{W}$ emulsion becomes a W/O emulsion.

- Ostwald ripening; is the growth of larger droplets at the expense of smaller ones and is related to the solubility gradient found between small and large droplets (17).

Emulsion stabilization has been examined through improvement of kinetic stability by using emulsifiers; such agents form a shielding layer around the droplets that may help protect them from aggregation by generating repulsive interactions. The most common emulsifiers used in the food industry are amphiphilic proteins, polysaccharides, phospholipids and small molecule surfactants (18).

Another common strategy that could improve food emulsions stability is the incorporation of biopolymers (thickenings agents); for instance, proteins have absorption properties at oil-water interfaces to form layers around oil droplets, and, in general, hydrocolloids act by increasing the viscosity or forming a gel network within the dispersing phase, thus delaying the instability processes. Additionally, some thickening agents (e. g. proteins, gum arabic and gum tragacanth) are also surface-active $(11,17)$.

Dehydration of oil-in-water emulsions that contain thickening agents is a common practice for the elaboration of food powders. Nowadays there are several food emulsions containing oils or polyunsaturated oils as carriers of flavors and other components; in the resulting product, the oil preserves its role as the disperse phase and is entrapped or microencapsulated in an amorphous material (23); however, in order to remove the smallest possible amount of water during drying processes, highly concentrated formulations $(>>10 \%)$ are very advantageous (24).

Despite there are reports that verify the opposite, it is extensively accepted that microencapsulation efficiency is affected positively by oil droplet size, the smaller and more uniform the droplets the more oil is covered per surface unit by the encapsulating matrix (23). Altering emulsion composition by changing fat and stabilizer, both in type and concentration, leads to products with different physical and sensory properties; however, the decrease of emulsion droplet size in the encapsulation (at nanoscale) of essential oils represents a feasible and efficient approach to improve the physical stability of the bioactive compounds, protecting them from the interactions with other formulation ingredients and, because of the subcellular size $(500 \mathrm{~nm})$, produces higher absorption through the activation of passive mechanisms of cell absorption (11, 25-27).

The droplet size could influence the equilibrium distribution of flavor molecules within an emulsion (28):

- For tiny droplets $(\mathrm{d}<100 \mathrm{~nm})$, the vapor pressure of a compound, contained inside such droplet, increases as the droplet size decreases, which could increase the headspace concentration. Nevertheless, for the majority of food emulsions this effect is unlikely to be significant.

- If an emulsifier is able to solubilize flavor molecules, a change in the total emulsifier concentration will change the flavor profile; so, when the droplet surface area increases the fraction of emulsifier molecules adsorbed to the droplet interfaces increases and the flavor distribution within an emulsion may be altered by change in droplet size.

There is considerable attention within the food and beverage industries in the utilization of ultrafine emulsions to encapsulate and deliver lipophilic functional agents, such as, colors, antimicrobials, micronutrients, nutraceuticals and flavors (29). Nanoemulsions (droplet size $<100 \mathrm{~nm}$ ) have gained recent interest among food manufacturers and scientists as novel delivery and encapsulation systems; given their smaller droplet size, they have low turbidity and are optically transparent; this property is of interest to the food industry as it enables the delivery of lipophilic flavors and bioactive ingredients in clear emulsions. Smaller size droplets also have the potential to improve the bioavailability of the core because of the increased surface area (29-31). Only emulsions with droplet size in the nanometer range obtained by shear methods are considered as nanoemulsions (16).

Other important advantage of nanoemulsions is their high physical stability; although they are still not thermodynamically stable, they have an extremely long kinetic stability that significantly exceeds that of larger emulsions (32). Nanoemulsions are sometimes referred to as 'Approaching Thermodynamic Stability' (29, 30).

The small droplet size of nanoemulsions makes them defiant to physical decay by gravitational separation, flocculation and/or coalescence. Nanoemulsions are resistant to creaming since Brownian motion is sufficient to defeat their low gravitational separation force. They are also resistant to flocculation because of greatly efficient steric stabilization. Most nanoemulsions are stabilized by synthetic surfactants which tend to have long hydrophilic tails of the order of 2-10 $\mathrm{nm}$. The high ratio of steric layer 
thickness to droplet diameter $(\delta / \mathrm{r}$ ratio) means that steric stabilization is very effective and even weak flocculation is prevented (33).

Nanoemulsions, however, are particularly prone to a growth in particle size over time by Ostwald ripening; this process is driven by the Kelvin effect where the small emulsion droplets have higher local oil solubility than the larger droplets because of the difference in Laplace pressures. The rate of Ostwald ripening is largely dictated by the solubility of the oil in the continuous phase $C(\infty)$ as described by Liftshitz and Slesov, and Wagner (LSW theory). The LSW theory assumes that the droplets of the dispersed phase are spherical, the distance between them is higher than the droplet diameter and the kinetics is controlled by molecular diffusion of the dispersed phase in the continuous phase. According to this theory, the Ostwald ripening rate in $\mathrm{O} / \mathrm{W}$ emulsions is directly proportional to the solubility of the oil in the aqueous phase. The aqueous phase solubility of an oil decreases linearly with oil molar volume, Vm (32-34).

A diversity of preparation methods have been developed to obtain a fine emulsion and these can be classified as either high energy or low energy approaches (35). Microemulsions are obtained through low energy methods; the droplets in a microemulsion are stabilized by a series of surfactants, generally in conjunction with a co-surfactant, which are necessary to further lower the interfacial tension. The use of microemulsions in food formulations has been restricted by the toxicity of surfactants and co-surfactants involved (31).

\section{HIGH ENERGY METHODS}

Emulsion formation is non-spontaneous and energy is required to produce the droplets. An emulsion is prepared by dispersing one immiscible liquid into another by using a process called homogenization wherein one of the phases gets dispersed in the other by forming small droplets. In contrast with the formation of small drops, the formation of large droplets (few micrometers) as is the case for conventional emulsions is fairly easy with high speed stirrers such as the rotor stator systems (mechanical devices) but do not provide a good dispersion in terms of droplet size and monodispersity. Indeed, the energy provided is mostly dissipated, generating heat and being wasted in viscous friction. Therefore, the additional free energy $\Delta$ Gf necessary to create the huge interfacial area of nanoemulsions is not obtained $(20,30,36)$.

Conventional emulsions require certain amount of energy to expand the interface, $\Delta A \gamma$ (where $\Delta A$ is the rise in interfacial area when the bulk oil with area $A_{1}$ produces a large number of droplets with area $A_{2} ; A_{2}>A_{1}, \gamma$ is the interfacial tension). Because $\gamma$ is positive, the energy to expand the interface is larger and positive. This energy term cannot be compensated by the small entropy of dispersion $T \Delta S$ (which is also positive) and the total free energy of formation of an emulsion, $\Delta \mathrm{Gf}$ is positive (1):

$\Delta \mathrm{Gf}=\Delta A \mathrm{y}-T \Delta S(30)$

The formation of small drops is not easy and this requires that a high shear stress supplies an amount of energy larger than the Laplace pressure ( $p$, the difference in pressure between inside and outside the droplet) gradient $(30,33,37)$ :

$p=y\left[\frac{1}{R 1}+\frac{1}{R 2}\right]$

In (2) $R l$ and $R 2$ are the main radii of curvature of the drop. As showed in (3) for a spherical drop, $R 1=R 2$ and:

$p=\frac{2 y}{R}$

$(30,38)$

This demonstrates that the internal pressure increases with an increase in interfacial tension $(y)$ and a decrease in droplet radius $(\mathrm{R})$ so that in order to break up a drop into smaller ones, the former must be strongly deformed up to the specific surface area reaches the point of disruption and this deformation increases $p$ of the resulting droplets $(30,37,38)$.

This can be shown when a spherical drop deforms into a prolate ellipsoid. For a spherical drop, there is only one radius of curvature $R a$, whereas for a prolate ellipsoid there are two radii of curvature $R b, 1$ and $R b, 2$. Consequently, the stress needed to deform the drop is higher for a smaller drop. Since the stress is generally transmitted by the surrounding liquid via agitation, higher stresses need more vigorous agitation, hence more energy is needed to create smaller drops $(30,38)$. Surfactants participate in a major role during formation of nanoemulsions: lowering the interfacial tension, $p$ is reduced and therefore the stress required to break up a drop is reduced (30).

High energy approaches such as high pressure homogenization systems and ultrasonics are capable of generating intense disruptive forces that breakup the oil and water phases and lead to the formation of tiny oil droplets, with or without the addition of surfactants (14, $31,35,39)$.

Ultrasonic emulsification is believed to occur through two mechanisms (40):

- Application of an acoustic field which produces interfacial waves that eventually result in the spread of the oil phase into the aqueous medium in the form of tiny droplets. 
- Application of low frequency ultrasound causes acoustic cavitation, that is, the formation and subsequent collapse of microbubbles by pressure fluctuations.

Ultrasound homogenization is the most popular way to produce nanoemulsions and nanoparticles for research purposes. It does not; however, appear practical for use on an industrial scale, for which pressure devices are often preferred. Scalable top-down approaches such as highpressure homogenization have already been effectively used in low-viscous fluids for emulsion preparation and microencapsulation; these technologies could provide high shear stress and inertial forces resulting in a decrease of the average droplet diameter and an increased interfacial area; hence, they are commonly used in food industry $(36,41-44)$. In addition, the local energy input of high pressure homogenization is comparable to ultrasound application, the main differences are found in the processing time; actually, droplet disruption and stabilization have to take place within shorter time as compared to ultrasound homogenization (45), i.e. ultrasound homogenization is a high energy/long time system (46).

In general, emulsification process involves two steps: first, deformation and disruption of droplets, which increase of the specific surface area of the emulsion, and secondly, the stabilization of this newly formed interface by surfactants (47).

\subsection{High pressure homogenization}

The principle of high pressure homogenization is simple: a coarse emulsion produced with a high-speed blender is forced under pressure through a narrow valve $(10-100 \mu$ diameter, designed for this specific high pressure application) by applying a large pressure gradient of 10 to 100 and even $500 \mathrm{MPa}$ in a short time (milliseconds). High pressure homogenizers can be equipped with different types of homogenizing valves with different geometries; for each of the different valves the mechanisms causing droplet breakup may vary; but basically the liquid processed by any type of homogenizer valve passes under high pressure and the emulsion is accelerated to velocities of up to hundreds of $\mathrm{m} / \mathrm{s}$ in the gap, such conditions in the "homogenizing gap" derive in the disruption of fat globules and form a finer emulsion $(26,34,42,45,48-53)$.

At present, some equipment may deliver pressures up to 150-200 MPa (high pressure homogenization, HPH) and even more for the latest developments, e.g. up to 300-500 MPa for ultra-high pressure homogenization (UHPH) (54).

Previous studies have shown that the minimum particle size possible using the high energy approach depends on homogenizer type and operating conditions (e.g., energy intensity, time, and temperature), sample formulation (e.g., oil type, emulsifier type, and relative concentrations), and the physicochemical properties of the constituent phases (e.g., interfacial tension and viscosity) (35). As mentioned above, the emulsification process by HPH can be schematically represented by two stages, the first consisting of droplet deformation and subsequent disruption, with the resulting increase of the surface area of the emulsion; and the second one, involving droplet stabilization by means of the adsorption of the emulsifier molecules at the newly formed interfaces (Donsì et al., 2012b).

The emulsion droplet size (EDS) is determined by the dynamic balance between two opposing processes; droplet breakup and recoalescence $(33,55)$. These processes take place given that if the timescale of surfactant absorption is longer than the timescale of collision, the fresh interface will not be completely covered and will lead to re-coalescence (an EDS increase), or "over-processing" (Jafari et al. [56] has more information about this topic).

The mechanisms for HPH involved in droplet break-up have not been completely elucidated; in fact, it is not possible to specify a single overall disruption mechanism for a certain type of emulsifier systems without taking the product parameters (e.g. viscosity of the two phases, interfacial tension), operating parameters (e.g. volume flow rate, temperature) and device parameters (e.g. valve geometry) into account. In the literature, different disruption mechanisms are generally emphasized as the cause of the droplet disruption in the high pressure homogenizer: simultaneous viscous stress, implosion of cavitation bubbles and interactions with turbulent eddies being the most predominantly found explanations $(51,37$, 57, 58).

For a given valve geometry, disruption is also influenced by product properties and operating conditions (26); detailed studies of carefully scaled models show no fragmentation at all in the valve gap, rather within the region of the valve gap and in the jet after the gap, where the flow is elongational and then turbulent, respectively. With the exception of small laboratory equipment, turbulent shear forces is said to be the predominant mechanism that contribute the most to droplet disruption; turbulent flows are characterized by the presence of eddies and chaotic velocity fluctuations; both shear forces and local pressure fluctuations (inertial forces) can come into operation. Inertial forces are usually predominant, but viscous forces may be involved in the homogenization process. Turbulent fragmentation can be seen to be controlled by two factors; the amount of dissipated energy, closely linked to the pressure, and the drop 
deformation time relative to the turbulent eddy life time, linked to disperse phase viscosity $(37,50,51,55,59,60)$. Whereas the viscosity of the continuous phase does not play a significant role on the disruption efficiency, the disperse phase viscosity or the viscosity ratio, defined as the ratio of the viscosity of the disperse phase to the viscosity of the emulsion phase $(\eta \mathrm{d} / \eta \mathrm{nem})$ or of the continuous phase $(\eta \mathrm{d} / \eta \mathrm{c})$, represents an important parameter (26). However, according with Qian and McClements (35), in homogenizers where shear forces play an important role, by increasing the viscosity of continuous phase the droplet diameter usually decreases, while through another technique, an increase of the viscosity in continuous phase leads to diminished coalescence frequency because it slows down the movement of droplets (61).

A drop with a higher viscosity will need a longer time for deformation when a given force acts upon it. If this time is of the same order or lower than the relevant time scales for the fragmentation mechanism, break-up will be partially controlled by this deformation process (51).

More recently Lee et al. (60) reported that two types of droplet break-up regimes are identified:

- Turbulent-inertial which occurs when the droplet size is similar in size to the smallest scale eddies in the system.

- Turbulent-viscous takes place when droplet sizes are decreased below the size of the smallest eddies in the system by the shearing forces created within these eddies. Droplet deformation and break-up in turbulent viscous flow is considered to be mechanistically similar to simple shear.

In laminar flow, viscous forces are mainly responsible for the flow and only shear forces lead to droplet deformation and subsequent disruption (37). The formation of emulsions in laminar shear regimes is only sensible in energy terms when the ratio of the viscosity of the disperse phase (vd) and the viscosity of the emulsion (ve) falls in the range: $0.1<\mathrm{vd} / \mathrm{ve}<1$ (62).

Cavitation means the formation of cavities filled with gas or vapor as static pressure decreases and their subsequent collapse as soon as the static pressure increases again (49). Cavitation can be generated by the passage of the liquid through a constriction such as an orifice plate or a valve. When the liquid passes through the constriction, boundary layer separation occurs and the kinetic energy associated with the liquid increases at the expense of the local pressure (63).

In the homogenization, according to the law by Bernoulli, the flow volume of liquid in a closed system per crosssection is constant. That means the reduction in the diameter leads to an increase in the dynamic pressure with the simultaneous decrease in the static pressure below the boiling point. A liquid boils when its vapor pressure is equal to the air/static pressure of the environment, in consequence, the liquid starts boiling at room temperature, leading to the formation of gas bubbles, which implode after leaving the homogenization gap and normal pressure conditions are reached again $(64,65)$.

Other two cavity formations are distinguished when static pressure falls below the critical value (49):

- Gas cavitation: the reduction of static pressure results in a lower solubility of the gas that could be dissolved in any liquid and, therefore, the formation of small gas-filled bubbles.

- Pseudo cavitation: in occasions a liquid also contains undissolved gas that is dispersed in the liquid in the form of microscopic bubbles. If the static pressure decreases, these bubbles will expand.

However, since these processes take much longer than the sudden collapse of bubbles filled with vapor, gas cavitation and pseudocavitation do not contribute to droplet disruption (49).

In high-pressure homogenizers, the pressure difference over the nozzle corresponds to the energy density (Ev), this is the mechanical energy input per volume of the zone where the droplets are disrupted (dispersing volume). When the stresses acting locally on the droplet exceed the retaining forces for a sufficiently long time, the droplet is disrupted. The result of disruption, expressed by a mean diameter $x$ (e.g. the z-average diameter) can be described as a function of energy density by:

$X=C E V^{-b}$

In (4), $b$ and $C$ are constant. Typical values of $b$ range from 1 for laminar elongational flow to about 0.6 for inertial forces in turbulent flow, and 0.75 for shear forces in turbulent flow. $\mathrm{C}$ depends on the efficiency of droplet disruption and $b$ is affected by the flow conditions in the dispersing volume $(26,66)$.

There are a number of limitations in using high energy methods to produce ultrafine emulsions, such as high initial equipment and operating costs, high power requirements, potential for equipment breakdown, and difficulties in producing very fine droplets from certain kinds of food ingredients, e.g. highly viscous oils or slowly adsorbing emulsifiers (29). The droplet stabilization that has to take place at extreme fast kinetics requires working at surfactant concentrations that are high enough (45).

The high wall shear forces resulting from liquid friction on the valve surface and conversion of kinetic energy into heat, as well as cavitation, lead to short-life heating phenomena; however, this can be controlled by efficient 
cooling devices. Moreover, classical high pressure homogenization requires the use of a coarse emulsion that should be prepared before $(45,67)$. When the purpose of the experiment is the encapsulation of fragile molecules such as peptides, proteins, or nucleic acid, often encountered in pharmaceutical or medical research, high energy methods may give rise to drug degradation, denaturalization or activity loss during processing (36). Suárez-Jacobo et al. (68) reported that the loss of $\beta$ carotene in apple juice during HPH could be due to the working pressure.

Other inconvenient of HPH is that, depending on processing conditions, the structure of thickeners/wall material can break-down and reduce their molecular weight when are subjected to such process, e.g. starch derivatives Modigb et al. (69) and Nilsson et al. (70) OSA starch, Wang et al. (71) waxy maize starch, Majzoobi et al. (72) Corn starch, Augustin et al. (73), resistant starch. Floury et al., (74) reported that methylcellulose polymers reduced their molecular weight after being subjected to high pressure and ultra-HPH process. Kasaai et al. (75) reported that polymers of chitosan with larger molecular size are preferentially degraded by HPH.

\subsubsection{High pressure systems}

Different equipments using high pressure technology are actually in development, either prototype or industrial scale equipment, depending on the nominal pressure level $(54,57)$. A classification of these systems can be based on the nozzle geometry and design and depends on the flow guidance, which is more useful than commonly classifying by taking into account the kind of construction, since the emulsifying nozzle is decisive for the efficiency of disruption using high pressure devices. They can be subdivided into $(56,76)$ :

- Radial diffusers (standard nozzles)

- Counter jet disperser

- Axial nozzle systems (orifice valves)

It is common that some homogenizers work with a configuration multistage; first valve frequently works under high pressures, with the main function of disrupting the droplets and producing smaller ones, whereas the second one works at low pressure, generally as $10 \%$ of the high pressure. This second valve has a positive effect on the efficiency of homogenization, preventing the droplet recoalescence. The backpressure produced by a second stage, promotes cavitation and improves the result of homogenization (37).

\subsubsection{Radial diffusers}

The radial diffuser (Fig. 1), so named due to the flow path in these nozzles and often referred as homogenizing valve or standard nozzle, is the most widespread HPH unit in industry $(37,56,76)$. For a given pump throughput, the homogenizing pressure is determined by the force acting on the axially movable valve plug and the size of the gap resulting from this (62).

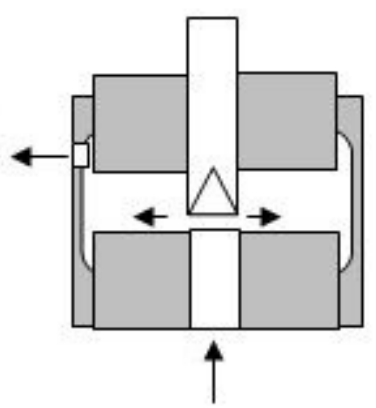

Fig. 1: Basic scheme of a radial diffuser system. After Schultz et al. (76).

A standard radial diffuser consists of a valve face, which causes a deflection of $90^{\circ} \mathrm{C}$ of the direction of the flow, and an axially mobile valve seat, which makes a variation of the slit width possible as well as with constant flow rate, a variation of the homogenizing pressure (Schulz et al., 2004). The coarse emulsion is pumped by means of a high pressure pump through a central inlet bore and forced through the radial gap between the valve seat and the valve plug. In its inlet bore the fluid accelerates a very short distance to a very high velocity $(37,76)$, the resulting strong pressure gradient between the inlet and outlet of the valve generates intense shear forces and extensional stress through the valve gap. The kinetic energy generated by the pressure energy applied is responsible for particle disruption to the submicron range (37); besides, as mentioned above, the effect of cavitation phenomena increases the homogenization efficiency.

The particle disruption in radial diffusers is predominantly due to inertial forces in turbulent flow. Disruption is also possible through shear forces in turbulent flow and cavitation (62). However, Schulz et al. (76) indicated that the droplet disrupting mechanism is located in the laminar extension flow at the inlet of the homogenization slit. Compared to the phenomena of droplet disruption in the inlet slit, the cavitation and turbulence may be neglected.

Avestin homogenizer is widely used in emulsion industries and its related work (77). Emulsiflex equipment from Avestin Company resembles a conventional homogenizer but with a specific novel valve design. Emulsiflex technology has been applied in laboratory systems that attain pressures up to 2200 bar $(\approx 215 \mathrm{MPa})$ and the designs are specifically adapted for high pressure use (78).

Using a radial diffuser type valve (Emulsiflex C-50), Lacroix et al. 79) evaluated the treatment of $\mathrm{HPH}$ on orange juice at $170 \mathrm{MPa}$. They reported that orange juices subjected to HPH were significantly more stable probably because of the modification of structure of pectin and also 
due to particle size reduction; besides, with a pre-warm treatment together with HPH, the flavor of juices was improved. On the other hand, small-scale machine from Avestin (Emulsiflex-C50) can be operated at a wide range of pressures up to 2000 bar (200 MPa) (77).

More recently, Nogueira et al. (80) analyzed (during 12 weeks) size and polidispersity index of different sweet fenel oil's formulations processing with an Emulsiflex-C5 at $\approx 70 \mathrm{MPa}$ for 5 cycles; the smallest droplet diameter $(\mathrm{d}=52.91 \mathrm{~nm})$ was found for the system with higher surfactant proportion, all formulation displayed a narrow size distribution. Four nanoemulsions showed a slightly increase of droplet size over time, which the authors suggest it could be attributed to Ostwald ripening and coalescence mechanism. Emulsiflex-C5 is actually a long-awaited combination of homogenizer and extruder. Caution is also needed to minimize oxidation and hydrolysis (81).

In other study with an Emulsiflex-C5 at 34.5, 69 and 103.5 MPa passing through three cycles, Kourniatis et al. (82) produced emulsions of orange essential oil with a narrower droplet size distribution using a mixture of nonionic surfactants at oil phase of $10 \mathrm{wt} \%$. The stability of the orange oil emulsion and their droplet size distributions in the presence of a pair of surfactant mixtures did not vary significantly with increasing processing pressure in the HPH. No stable emulsions were obtained at the same conditions (three different pressures with three cycles) with pure nonionic surfactants; this behavior can be attributed to the low interfacial tensions obtained for these systems.

Yang et al. (83) homogenized citral emulsion with palm kernel fat and soy lecithin by using Emulsiflex-C3, equipment for six cycles at the pressure of $150 \mathrm{MPa}$. They observed that the incorporation of antioxidant agents increases the particle size; however, no phase separation was observed for any of the emulsion samples at 25 and $50^{\circ} \mathrm{C}$ storage and the analyses showed that particle size increased slightly at any temperature but in samples stored at $50^{\circ} \mathrm{C}$ such increase was higher, they explained that it is due to the particles moving more rapidly. When the authors evaluated citral's chemical stability under acidic condition ( $\mathrm{pH}$ 3.0) they established that encapsulation of citral in $\mathrm{o} / \mathrm{w}$ nanoemulsions could improve its chemical stability and reduce the production of many off-flavor compounds.

With an homogenizer Niro- Soavi NS 1001-L, a twostage piston homogenizer, Kim et al. (84) using whey protein isolate, soy protein isolate, sodium caseinate and gum arabic as encapsulating agent elaborated emulsions of orange oil at 70,140 , or $210 \mathrm{~kg} \mathrm{~cm}-2(6.86,13.73$ and $20.59 \mathrm{MPa}$ respectively) at first stage of homogenization and $35 \mathrm{~kg} \mathrm{~cm}-2$ (3.43MPa) at second stage of homogenization; they observed that the droplet size and the depth of the cream layer were significantly affected by encapsulating agent and percent oil load but not by variations in homogenization pressure of 70 and $210 \mathrm{~kg}$ $\mathrm{cm}-2$; however, soy protein isolate emulsions were most stable than the rest of the encapsulating materials and the size of its droplets was smaller too. Sodium caseinate and gum arabic did not encapsulate orange oil at the higher oil concentrations as effectively as at lower oil concentrations.

Bringas-Lantigua (85 prepared a microencapsulated product of lime essential oil, gum arabic and maltodextrin at 10-50 $\mathrm{MPa}$ for two passes using a Niro Soavi homogenizer. They observed that the surface oil contents of the microencapsulated products ranged between 0.001 to $0.009 \mathrm{wt} \%$ total solids, the $\operatorname{EDS}\left(\mathrm{D}_{43}\right)$ was $2.9 \mu \mathrm{m}$. Low surface oil content is very important for providing storage stability to flavorings that are subject to oxidative deterioration.

Another study in a two-stage pressure homogenizer Panda GEA Niro Soavi (86) using maltodextrin and gum arabic as carriers to obtain lemon aroma powder, observed that particle diameters of the respective emulsion for high shear homogenization were significantly higher than diameters for $\mathrm{HPH}$ (30 and $60 \mathrm{MPa}$ and 10 and $20 \mathrm{MPa}$ on the first and second level respectively); in addition, whereas an increase of aroma addition caused an increase in diameter after high shear homogenization, the diameter size did not change after HPH; moreover, the modification of the homogenization pressure caused no change in the mean diameter of droplets, independently of lemon oil addition.

Costa-Garcia et al. (87) concluded that in order to achieve the highest retention of basil oil, the best conditions for its encapsulation with gum arabic were oil concentration about $10-14 \%$ and homogenization pressures greater than $50 \mathrm{MPa}$ in the first stage (PANDA2K, Niro Soavi). In addition, authors observed that the systems were positively affected by an increase in homogenization pressure when obtaining a lower EDS (mean diameter varied from 0.46 to $0.91 \mu \mathrm{m}$ ); furthermore, particles produced from emulsions with a small droplet size presented higher oil retention. However, the homogenization pressure was the factor that most affected emulsion stability after $24 \mathrm{~h}$ of homogenization. The emulsions produced under higher homogenization pressures were less stable, showing higher coalescence level.

In Niro VHP (very high pressure) homogenizers, the homogenizing effect is caused by the product entering the valve inlet under pressure, and as it passes through the minute gap; the velocity rapidly increases while the pressure rapidly decreases to atmospheric pressure. The 
homogenizing efficiency is due to a combination of the pressure applied and the geometry of the valve (88).

In APV-Gaulin high-pressure homogenizer (Fig. 2) the fluid is fed axially into the valve seat, and then accelerated radially into the gap between the valve and seat. When the fluid leaves the gap, it becomes a radial jet that stagnates on an impact ring before leaving the homogenizer (57).

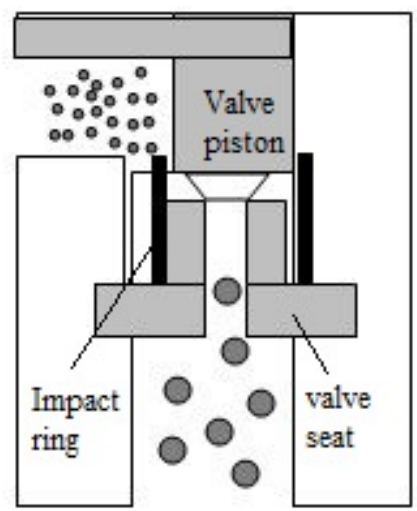

Fig. 2: Schematic view of APV-Gaulin valve. After Floury et al. (50)

Djordjevic et al. (15), using an homogenizer APV-Gaulin at near $21 \mathrm{MPa}$ for four passes, obtained emulsion systems of limonene and citral stabilized with sodium dodecyl sulfate (SDS), SDS-chitosan, and gum arabic with initial mean particle diameters $\left(d_{43}\right)$ of $0.25,0.41$, and $1.1 \mu \mathrm{m}$, respectively. Emulsions containing SDScoated were physically more stable droplets during storage than the others. At the end, SDS-chitosan system was not effective for preventing the degradation of citral in o/w emulsions as compared to gum arabic; however, it was more effective than gum arabic in preventing limonene degradation.

Mirhosseini et al. (89) homogenized cold pressed orange oil using a mixture of gums arabic and xanthan passed through a high pressure homogenizer (APV-Gaulin) for three times (30, 28 and $25 \mathrm{MPa})$. The authors reported that the mixed surface active materials behaved totally different from one and another; first, they observed a negative relationship between gum arabic and emulsion stability, because emulsions containing gum arabic are more susceptible to depletion flocculation; and second, high concentration of gum xanthan as an anionic polysaccharide led to increase the negatively charged $\zeta$ potential and subsequently the emulsion stability.

Another manufacturer of homogenizers with specifications similar to that of APV-Gaulin is APV Rannie AS (90). In most cases, with the standard valve geometry (from APV-Gaulin or Rannie), turbulence is said to be the predominant mechanism.
Using a Rannie homogenizer, Miettinen et al. (91) prepared different matrices of rapeseed oil (5 or $50 \%$ ), using an emulsifier $(1 \% \mathrm{w} / \mathrm{w}$, modified potato starch or sucrose estearate). The matrices were flavored with either 2,3-butanedione (more polar) or linalool (nonpolar) such emulsions were homogenized four times at $30 \mathrm{MPa}$ (which gave a smaller EDS) and $10 \mathrm{MPa}$, such emulsions were very stable during 3 weeks. They observed greater release of linalool from pure water and then from emulsions containing $5 \%$ fat, therefore the release levels from pure oil and $50 \%$ fat emulsions were quite similar; the more polar compound was more easily released from pure oil than from water matrix. However, in the case of emulsion matrices, there was a trend of greater release from the emulsions containing less fat.

Also in the latter work, the effect of EDS was observed only for the nonpolar compound, the release was enhanced from small droplets; as well, the effect of the type of emulsifier was detected in the case of 2,3butanedione, so that more aroma was released when the sucrose stearate was used. A subsequent analysis showed that amount of linalool was greatest in the headspace of the water matrix and smallest in the headspace of the pure oil matrix; while the amounts of 2,3-butanedione in the headspaces of water and oil matrices were similar. No significant effect of the EDS on the headspace concentration of 2,3-butanediona or linalool was observed.

In the case of a convergent high pressure-valve with sharp angles as Stansted Fluid Power Ltd (92) even achieves pressure up to $350 \mathrm{MPa}$. However, the geometry and the gap size of the valve are then different from the classically studied valve homogenizer such as the APVGaulin homogenizer. HPH up to $350 \mathrm{MPa}$ has recently received great attention since it represents an important innovation to be used for sterilizing products in situ and to modify the texture of emulsions or biopolymers, for food or pharmaceutical applications (50).

An study (93) reported the reduction of EDS (0.84 to 1.16 $\mu \mathrm{m}_{23}$ ) with the increase in the homogenization pressure for a matrix consisting of gum arabic-sucrose-gelatin $(1: 1: 1)$ with a ratio $(\mathrm{w} / \mathrm{w})$ of $9: 1$ (total solids: limonene) subjected to a range of ultra-high pressure (50-250MPa) homogenization using an ultra high pressure homogenizer Stansted Fluid Power Ltd. The authors observed that emulsions homogenized at $100 \mathrm{MPa}$ gave the highest amount $(84 \%)$ of limonene encapsulation after freeze drying process. Increases in homogenization pressure beyond 100MPa led to decreases limonene encapsulation.

\subsubsection{Counter jet dispersers}

Jet dispersers involve two fluid jets of the coarse emulsion (each from opposite bores) that collide with one 
another to disrupt particles, the diameters of the bores in jet dispersers are typically $0.3-0.5 \mathrm{~mm}$. Unlike radial diffusers the nozzle in jet dispersers contain no moving parts so they can be used at very high pressures, up to $300-400 \mathrm{MPa}(54,56,62)$. For a given constant viscosity of the emulsion the homogenizing pressure is adjusted only by means of the volume flow rate $(62,76)$.

Droplets are disrupted predominantly due to laminar elongational flow ahead of the bores (56). It is very important to note, that it is not shown yet that the droplets are disrupted in the elongational flow itself. On the contrary, it is more probable that the droplets are deformed in the elongational flow regime and then are disrupted due to a perturbation in a zone following the elongational flow. Nevertheless, the elongational flow is mandatory for droplet disruption (62).

Since the mid 1990's, the use of microfluidizers has gained prevalence (40). Microfluidization process is based on the same principle that counter jet dispersers but with different design. The equipment has two types of valves (interaction chambers). In the Y-type interaction chamber (Fig. 3, right) of microfluidizer the premix stream is divided into two fluid jets at the inlet of the chamber and the fluid velocity is accelerated due to a sudden decrease in the pipe diameter, the two streams of liquid then collide with one another from two opposite microchannels leading to enhanced particle disruption $(37,54,56,78,94)$.

In a Z-type interaction chamber (Fig. 3, left), an incoming fluid stream under high pressure is forced through one or more zigzag microchannel changing a few times the direction of the flow leading to particle collision and shear forces able to disperse particle agglomerates or reduce particle size. Fluid emerging from these channels impacts the walls after which it is discharged from the unit atmospheric pressures. There is no head-on collision of two fluids streams $(65,95)$. $\mathrm{Z}$ chambers are classically located downstream of one or extra Y-type chambers (96).

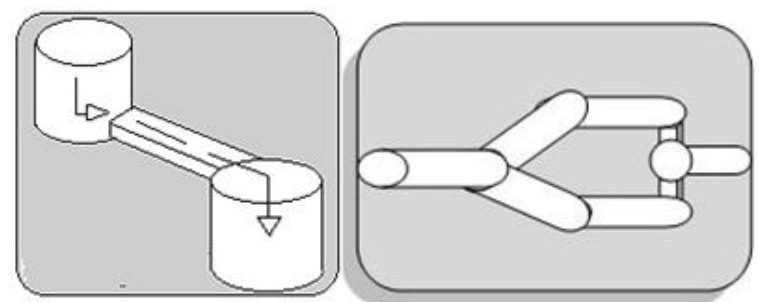

Fig. 3: Scheme of microfluidizer Z-type (Left) and Y-type (Right) interaction chambers. After Thies (95)

A number of previous studies have shown that microfluidization is particularly efficient at creating ultrafine emulsions from food-grade ingredients, such process is most commonly used in the pharmaceutical industry for the production of fine emulsions but recently it has been widely used in the food industry to produce ultrafine emulsions $(29,97)$.

Laminar extension flow is considered responsible for droplet disruption at the inlet of the chamber. Inside the chamber the flow stream is forced by high pressure through microchannels, changing its flow direction, leading to enhanced particle collision and forming an impingement plane by the collision of the two jet streams (each with approximately $75 \mu \mathrm{m}$ diameter). The region of impingement is characterized by its fast dissipation of turbulent kinetic energy. The droplet break-up occurs during energy dissipation of the jets impinging creating high shear forces for droplet deformation and break-up, which can provide an exceptionally fine emulsion. In general, inertial forces in turbulent flow along with cavitation are predominantly responsible for droplet disruption in microfluidizer. Disruption in laminar elongational flow is also possible, especially when the emulsion has high viscosity $(54,56,60,98)$.

Due to the spatial and temporal inhomogeneity of the pulsed microfluidic flow, it is generally necessary to recirculate the emulsion through the region of high shear or to pass it through the device several times (19).

Rao and Mcclements (99) subjected to microfluidization for three passes at $\approx 63 \mathrm{MPa}$ different formulation of lemon oils $(10 \% \mathrm{w} / \mathrm{w})$. The authors observed that surfactant-oil ratio and thermal treatment had a major impact on the nature of the colloidal dispersions formed from lemon oil. The colloidal dispersions containing $10 \%$ of surfactant had a droplet mean diameter extremely small; besides, differences in the chemical composition of lemon oils may impact the type, stability and properties of colloidal dispersions formed.

In other study (100) focused in the influence of lemon oil composition on the formation and stability of oil-in-water emulsions, the authors homogenized lemon oil (10 wt. \% lemon oil-in water emulsions) with 1, 3, 5 and 10 folds at $\approx 63 \mathrm{MPa}$ for three cycles. They reported that during homogenization the mean volume-weighted particle diameter decreased with increasing lemon oil fold and regards stability of storage of such emulsions this depended strongly on lemon oil fold stability to droplet growth increased as the oil fold increased, they discussed that the presence of relatively high levels of lemon oil constituents with low water-solubility in high fold oils may have been able to inhibit droplet growth by generating a compositional ripening effect that opposed the Ostwald ripening effect.

In the same way, a different study (101) about lemon oil solubilization in mixed surfactant, the authors prepared a $10 \mathrm{wt} \%$ lemon oil-in-water nanoemulsion at the same 
conditions of pressure and microfluidization cycles that the as above and they obtained droplets with a mean diameter of $105 \mathrm{~nm}$.

Cho and Park (102) concluded that the stability of a primary emulsion of five different flavors (ethyl propionate, butyl acetate, 2-heptanone, limonene, and octanol-1) was related to a high amount of gum arabic and the subsequent homogenization by microfluidization (droplet mean diameter obtained of $5.7 \mu \mathrm{m}$ ); as a consequence, this influenced the stability of a successively obtained multiple emulsion o/w/o. The authors also observed that there were no significant differences among different homogenization pressures (41 and $82 \mathrm{MPa}$ ) on primary emulsion stability.

Lim et al. (103) homogenized by microfluidization 4folds orange oil at $\approx 48 \mathrm{MPa}$ for five cycles mixing with different content of modified starch and ester gum. They observed a slight reduction of mean droplet size by using modified starch; the mean droplet diameters of all emulsions were appreciably higher than the initial after 15 days storage. In the presence of $>9 \%$ of ester gum the emulsions were physically stable during storage; however, at lower concentration the emulsions exhibited appreciable droplet growth. By mixing ester gum with modified starch it was produced a stable orange oil emulsion at starch levels from $2 \%$ to $10 \%(\mathrm{w} / \mathrm{w})$.

Soottitantwat et al. (104) observed a decrease in retention of the active principle and a higher surface oil content with an increase of the emulsion droplet diameter when they obtained microcapsules by spray-drying of Dlimonene (insoluble flavor), such behavior occurred especially in the range of the 0.5 to $2.0 \mu \mathrm{m}$ mean emulsion size, which indicated that, for the proper wall materials, the emulsion droplet size is a significant factor for the retention of such flavor. In the case of the ethyl butyrate and ethyl propionate (moderately soluble), larger emulsion droplets decreased the retention; however, such retention had a maximum at the optimal value of the mean droplet diameter, while a fine emulsion caused a decrease in the retention of both the ethyl butyrate and ethyl propionate. The coarse emulsions were subjected to microfluidization process at $82.8 \mathrm{MPa}$.

In other work (105), the authors reported similar results when subjected an emulsion of D-limonene to the same condition of microfluidization than above for obtaining microcapsules of such essential oil; they concluded that, in addition to the effect of emulsion droplet size on the retention during spray drying, the EDS also affected the stability of encapsulated flavor powder. The small flavor size in the powder showed lower stability than the large flavor size.

In a study where D-limonene, together with fish oil, was used as model oil (61) they were produced finer emulsions using a microfluidizer from 20 to $124 \mathrm{MPa}$ by 1 to 4 cycles, among other results it was reported that at the lower energy inputs, there was a significantly decrease (nano-range) in emulsion size; however, at higher pressures and cycles microfluidization not only was not helpful, but also actually led to an increase in droplet size (Fig. 6), posterior analyses confirmed that occurred the over-processing phenomenon. The authors concluded that moderate pressures of about 42-63 MPa were responding better than higher or lower pressures and recirculation cycles of 1-2 were optimum.

Jafari et al. (46) compared homogenization systems as microfluidization and ultrasound preparing an emulsion of D-limonene dispersed in an aqueous matrix of modified starch and maltodextrin. The authors concluded that ultrasound was able to produce emulsions with EDS as small as microfluidized emulsions with the advantage of no occurrence of over-processing; however, the EDS obtained was in order of microfluidizer < ultrasound and EDS distribution was in order of microfluidizer < ultrasound with a main disadvantage of ultrasound emulsions was their slightly wider distributions and their dependence on preemulsion preparation method, other conclusion was that microfluidization at moderate pressures $(60 \mathrm{MPa})$ for minimum cycles can produce emulsions with fairly small sizes (about $500 \mathrm{~nm}$ ).

The limiting aspect of this technology is the pressure delivered by the equipment which is linked to the flow of the liquid and the equipment design (78).

\subsubsection{Orifice valves}

It is the simplest construction form for a homogenizing nozzle (Fig. 4). Like the counter-jet dispersers, the nozzle-aggregates also contains no movable part so they can be in use at very high pressures; however, contrary to the counter-jet stream, the nozzle-aggregates have an axial flow direction with bores that are typically $0.3-0.5$ $\mathrm{mm}$ in diameter and an inlet head of the orifice plate that is $10-60 \mathrm{~mm}$ in diameter. Laminar elongational flow ahead of the bores is responsible for droplet disruption in those systems $(37,56,62,76)$.

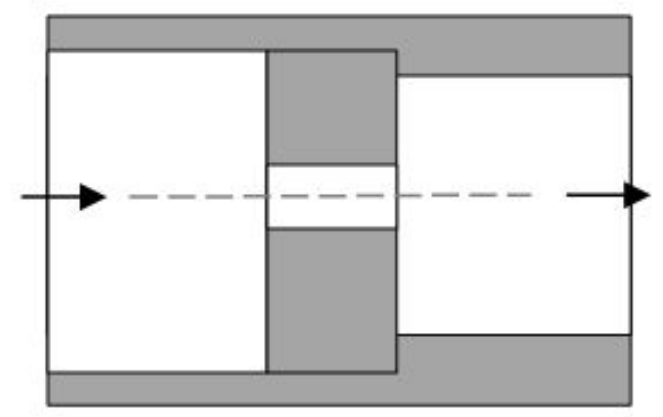

Fig. 4: Scheme of orifice valve. After Shultz (76). 
With a combined orifice valve (Fig. 5) smaller mean droplets diameters can be produced than with simple orifices. This can be attributed to a reduction of droplet coalescence by the turbulence chamber (76).

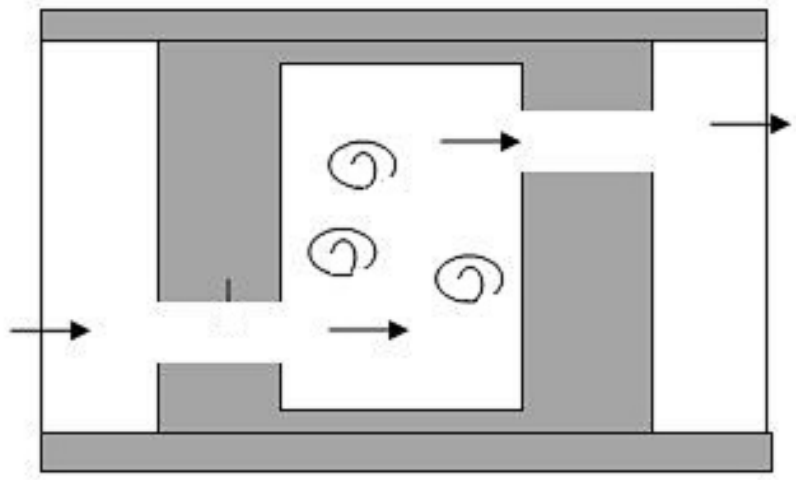

Fig. 5: Scheme of combined orifice valve. After Shultz et al. (76).

Donsi et al. (106) reported that using a Nano DeBEE Electric Bench-top Laboratory homogenizer at $350 \mathrm{MPa}$ and ten times, obtained a stable nanoemulsion $(365 \mathrm{~nm})$ with pure D-limonene and modified starch as an emulsifier. Also D-limonene was encapsulated, alone or blended with sunflower oil (1:1), into stable delivery systems made of Tween 20/ glycerol monooleate based nanoemulsions, with a very fine mean droplet diameter (from 130 to $155 \mathrm{~nm}$ ).

Donsi et al. (107) obtained an emulsion with a very narrow droplet size distribution of D-limonene and transcinnamaldehyde into a lipid phase composed of sunflower oil and different emulsifiers (soy lecithin, tween 20 and glycerol monooleate, sucrose palmitate and NUTRALYS). The authors used a Nano DeBEE Electric Benchtop Laboratory (5 passes at $300 \mathrm{MPa}$ ) which led to a mean droplet size comprised between $100 \mathrm{~nm}$ and 200 $\mathrm{nm}$.

\section{CONCLUSION}

Thanks to these researches, it has been possible to establish relationships that help to understand the mechanism of stability of dispersed systems in order to mitigate those phenomena that cause deficiencies in the kinetic behavior of such systems, and that result in loss of product quality. This could allow the incorporation of appropriate models that provide the critical points and the main factors for scaling high pressure homogenization technologies at industrial level.

This review allows analyzing that it is possible to apply high-pressure homogenization process in emulsion flavored systems to improve their stability and to reduce emulsion droplet size; however, increasing the homogenization pressure and number of passes or cycles could be detrimental to these parameters.
Other factors that could have an important impact on stability and droplet size during high pressure homogenization are type and ratio of wall material and emulsifier, both as a mixture or alone. Nature and ratio of flavor principle may influence the final results too.

The so named radial diffusers (or standard nozzles) are the most widespread systems for high pressure homogenization of flavored emulsions, and exist a number of works that report the use of different type of radial diffusers valves in the flavored emulsion systems; in contrast, in the valves with a jet disperses conformation it was found that microfluidizer (a counter-system) prevails over other systems in the same category and also is clear that microfluidizers are the most used high pressure homogenizers in research works on the improvement of stability and emulsion droplet size in flavored emulsions, currently. Conversely, orifice valves are the homogenization systems that it has been less used, so there may be a great opportunity in this area of study. It is interesting that a large percentage of studies of high pressure homogenization have been focused on citric oil (as orange oil and lemon oil) and limonene as a part of oil phase. It would be expected that the study of the effects of high pressure homogenization shall be extended to a wider range of essential oils, plant extracts, flavoring compound and raw materials. Besides it is expected that increase the number of studies about sensory and analytical analyses that report the effect of high-pressure homogenization on flavor molecules e.g. oxidation, break up and off-flavor formation.

It is important to point that compounds which impart aroma could possess some biological activity and, although currently there are groups investigating on this topic, the effect that high pressure homogenization may generate over such activity could be a promising field of research.

Despite most reports recommend a moderate homogenization pressure and a few passes or cycles, the emerging of equipment that can reach ultra-high homogenization pressures allows for collecting information about working with emulsions of flavor compounds at such conditions.

\section{ACKNOWLEDGEMENTS}

We are grateful for the financial support of the Consejo Nacional de Ciencia y Tecnología (CONACYT) through doctoral scholarship 20151382 and proyect SAGARPACONACyT 190442. Ocampo-Salinas is grateful for the financial support of CONACYT with register number 275972. 


\section{REFERENCES}

[1] Landy P., Courthaudon J., Dubois C. and Voilley A. 1996. Effect of Interface in Model Food Emulsions on the Volatility of Aroma Compounds. J. Agric. Food Chem. 44:526-530.

[2] Milanovic J., Manojlovic V., Levic S., Rajic N., Nedovic V. and Bugarski B. 2010. Microencapsulation of flavors in carnauba wax. Sensors. 10:901-912.

[3] Druaux C. and Voilley A. 1997. Effect of food composition and microstructure on volatile flavour release. Trends in Food Science \& Technology November. 8: 364-368

[4] Madene A., Jacquot M., Scher J. and Desobry S. 2006. Flavour encapsulation and controlled releasea review. International Journal of Food Science and Technology. 41:1-21.

[5] Covarrubias-Cervantes M., Bongard S., Champion D. and Voilley A. 2005. Effects of the nature and concentration of substrates in aqueous solutions on the solubility of aroma compounds. Flavour Fragr. J. 20:265-273.

[6] Kühn J., Considine T. and Singh H. 2006. Interactions of milk proteins and volatile flavor compounds: implications in the development of protein foods. Journal of Food Science. 71(5):72-82.

[7] Marcuzzo E., Sensidoni A., Debeaufort F. and Voilley A. 2010. Encapsulation of aroma compounds in biopolymeric emulsion based edible films to control flavour release. Carbohydrate Polymers. 80:984-988.

[8] Cheong K.W., Tan C.P., Mirhosseini H., JoanneKam W. Y., Abdul Hamid N.S., Osman A. and Basri M. 2014. The effect of prime emulsion components as a function of equilibrium headspace concentration of soursop flavor compounds. Chemistry Central Journal. 8:23.

[9] Roos K. 2003. Effect of texture and microstructure on flavour retention and release. International Dairy Journal. 13:593-605.

[10] Relkin P., Fabre M. and Guichard E. 2004. Effect of Fat Nature and Aroma Compound Hydrophobicity on Flavor Release from Complex Food Emulsions. J. Agric. Food Chem. 52:6257-6263

[11] Arancibia C., Jublot L., Costell E. and Bayarri S. 2011. Flavor release and sensory characteristics of $\mathrm{o} / \mathrm{w}$ emulsions. Influence of composition, microestructure and rheological behavior. Food Research International. 44:1632-1641.

[12] Bayarri S., Taylor A.J. and Hort J. 2006. The Role of Fat in Flavor Perception: Effect of Partition and Viscosity in Model Emulsions. J. Agric. Food Chem.54:8862-8868.
[13] Given P. 2009. Encapsulation of Flavors in Emulsions for Beverages. Colloid \& Interface Sci. 14(1):43-47.

[14]Rao J. and McClements D.J. 2011. Formation of Flavor Oil Microemulsions, Nanoemulsions and Emulsions: Influence of Composition and Preparation Method. J. Agric. Food Chem. 59:50265035

[15]Djordjevic D., Cercaci L., Alamed J., McClements D.J. and Decker E.A. 2007. Chemical and physical stability of citral and limonene in sodium dodecyl sulfate-chitosan and gum Arabic stabilized. J. Agric. Food Chem. 55:3585-3591.

[16] Gutiérrez J. M., González C., Maestro A., Solè I., Pey C. M. and Nolla J. 2008. Nano-emulsions: New applications and optimization of their preparation. Current Opinion in Colloid \& Interface Science. 13:245-251.

[17] Rousseau D. 2000 Fat crystals and emulsion stability. A review. Food Research International. 33:3-14

[18] Guzey D. and McClements J. 2006. Formation, stability and properties of multilayer emulsions for application in the food industry. Advances in Colloid and Interface Science. 128-130:227-248.

[19] Mason T.G., Wilking J.N., Meleson K., Chang C.B. and Graves S.M. 2006. Nanoemulsions: formation, structure, and physical properties. J. Phys.: Condens. Matter 18:635-666.

[20]Hebishy E., Buffa M., Guamis B. and Trujillo A.J. 2013, Stability of sub-micron oil-in-water emulsions produced by ultra high pressure homogenization and sodium caseinate as emulsifier, AIDIC Conference Series, 11:161-170.

[21] McClements D.J. and Dungan S. 1995. Light scattering study of solubilization of emulsion droplets by non-ionic surfactant solutions. Colloids and Surfaces. 104:127-135.

[22] Narsimhan G. and Wang Z. 2008. Guidelines for processing emulsions-based foods. 349-394. In: Hasenhuelttl G. L. and Hartel R. W. Food emulsifiers and their applications. Springer, $2^{\text {nd }}$ Edition. New York, NY. USA.

[23] Holgado F., Marquez-Ruiz G., Dobarganes C. and Velasco J. 2013. Influence of homogenization conditions and drying method on physicochemical properties of dehydrated emulsions containing different solid components. International Journal of Food Science and Technology. 48:1498-1508.

[24] Krause K.P and Müller R.H. 2001. Production and characterization of highly concentrated nanosuspensions by high pressuee homogenization. International Journal of Pharmaceutics. 214:21-24. 
[25] Ahmed K., Li Y., McClements D.J. and Xiao. 2012. Nanoemulsion- and emulsion-based delivery systems for curcumin: encapsulation and release properties. Food Chemestry. 132:799-807.

[26] Donsì F., Annunziata M., Vincensi M. and Ferrari G. 2012b. Design of nanoemulsion-based delivery systems of natural antimicrobials: Effect of the emulsifier. Journal of Biotechnology. 159: 342-350

[27] Sessa M., Balestrieri M.L., Ferrari G., Servillo L., Castaldo D., D’Onofrio N., Donsi F. and Tsao R. 2014. Bioavailability of encapsulated resveratrol into nanoemulsion-based delivery systems. Food Chemistry. 147:42-50.

[28] MacClements. D.J. 2004. Food emulsions: principles,practices and Techniques. Taylor and Francis. $2^{\text {nd }}$ edition.

[29] Yang Y., Marshall-Breton C., Leser M.E., Sher A.A. and McClements D.J. 2012. Fabrication of ultrafine edible emulsions: Comparison of high-energy and low-energy homogenization methods. Food Hydrocolloids. 29:398-406

[30] Tadros T., Izquierdo P., Esquenab J., Solansb C. 2004. Formation and stability of nano-emulsions. Advances in Colloid and Interface Science. 108 109:303-318.

[31] Augustin M.A. and Hemarb Y. 2009. Nano- and micro-structured assemblies for encapsulation of food ingredients. Chem. Soc. Rev. 38:902-912.

[32] Erdmann M.E., Zeeb B., Salminen H., Gibis M., Lautenschlaegerb R. and Weiss J. 2015. Influence of droplet size on the antioxidant activity of rosemary extract loaded oil-in-water emulsions in mixed systems. Food Funct. 6:793-604.

[33] Wooster T.J., Golding M. and Sanguansri P. 2008. Impact of oil type on Nanoemulsion. Formation and Ostwald Ripening Stability. Langmuir. 24:1275812765

[34] Solans C., Izquierdo P., Nolla J., Azemar N., and Garcia-Celma M. J. 2005. Nano-emulsions. Current Opinion in Colloid \& Interface Science. 10:102110.

[35] Qian C. and McClements D.J. 2011. Formation of nanoemulsions stabilized by model food-grade emulsifiers using high-pressure homogenization: Factors affecting particle size. Food Hydrocolloids. 25:1000-1008.

[36] Anton N., Benoit J.P. and Saulnier P. 2008. Design and production of nanoparticles formulated from nano-emulsion templates-A review. Journal of Controlled Release. 128:185-199.

[37] Santana R.C., Perrechil F.A. and Cunha R.L. 2013. High- and Low-Energy Emulsifications for Food
Applications: A Focus on Process Parameters. Food Eng Rev. 5:107-122.

[38] Lee L. L., Niknafs N., Hancocks R. D. and Norton I. T. 2013. Emulsification: Mechanistic Understanding. Trends in Food Science \& Technology 31:72-78.

[39] Cano-Sarmiento C., Monroy-Villagrana A., Alamilla-Beltrán L., Hernández-Sánchez H., Cornejo-Mazón M., Téllez-Medina D.I., JiménezMartínez C. and Gutiérrez-López G.F. 2014. Micromorphometric characteristics of $\alpha$-tocopherol emulsions obtained by microfluidization. Revista Mexicana de Ingeniería Química. 13(1):201-212.

[40] Kentish S., Wooster T.J., Ashokkumar M., Balachandran S. Mawson R. and Simons L. 2008. The use of ultrasonics for nanoemulsion preparation. Innovative Food Science Emerging Technologies. 9: 170-175.

[41]Dimakou C.P., Kiokias S. N., Tsaprouni L. V. and Oreopoulou V. 2007. Effect of Processing and Storage Parameters on the Oxidative Deterioration of Oil-in-Water Emulsions. Food Biophysics. 2:3845

[42] Innings F. and Tragardh C. 2007. Analysis of the flow field in a high-pressure homogenizer. Experimental Thermal and Fluid Science. 32:345354.

[43] Wang Y., Li D., Wang L. and Xuec J. 2011. Effects of high pressure homogenization on rheological properties of flaxseed gum. Carbohydrate Polymers. 83:489-494.

[44] Donsì F., Sessa M. and Ferrari G. 2012a. Effect of Emulsifier Type and Disruption Chamber Geometry on the Fabrication of Food Nanoemulsions by High Pressure Homogenization. Ind. Eng. Chem. Res. 51:7606-7618.

[45]Hecht L. L., Wagner C., Landfester K., and Schuchmann H. P. 2011. High-Pressure Homogenization. Langmuir. 27:2279-2285.

[46] Jafari S.M., He Y. and Bhandari B. 2007b. Production of submicron emulsions by ultrasound and microfuidization techniques. Journal of Food Engineering. 82:478-488.

[47] Brösel S. and Schubert H. 1999. Investigations on the role of surfactants in mechanical emulsification using a high-pressure homogenizer with an orifice valve. Chemical Engineering and Processing. 38:533-540.

[48] Desrumaux A. and Marcand J. 2002. Formation of sunflower oil emulsions stabilized by whey proteins with high-pressure homogenization (up to 350 $\mathrm{MPa}$ ): effect of pressure on emulsion characteristics. 
International Journal of Food Science and Technology. 37:263-269

[49]Freuding B. Tesch S. and Schubert H. 2003. Production of emulsions in high-pressure homogenizers- Part II: Influence of cavitation on droplet breakup. Eng. Life Sci. 3:266-270.

[50]Floury J., Legrand J. and Desrumaux A. 2004b. Analysis of a new type of high pressure homogeniser. Part B. study of droplet break-up and recoalescence phenomena. Chemical Engineering Science. 59:1285-1294.

[51]Håkansson A., Tragårdh C and Bergenståhl B. 2009a. Dynamic simulation of emulsion formation in a high pressure homogenizer. Chemical Engineering Science. 64:2915-2925.

[52] Pedras, M.M., Pinho, C.R.G., Tribst A.A.L. Franchi M.A. and Cristianini M. 2012. The effect of high pressure homogenization on microorganisms in milk. International Food Research Journal. 19(1):15.

[53] Becker P.J. Puel F., Dubbelboer A., Janssen J. and Sheibat-Othaman N. 2014. Coupled population balance-CFD simulation $\mathrm{f}$ droplet breakup in a high pressure homogenizer. Computers and Chemical Engineering. 68:140-150.

[54] Cortés-Muñoz M., Chevalier-Lucia D. and Dumay E. 2009. Characteristics of submicron emulsions prepared by ultra-high pressure homogenization: Effect of chilled or frozen storage. Food Hydrocolloids 23:640-654.

[55]Floury J., Desrumaux A. and Lardieres J. 2000. Effect of high-pressure homogenization on droplet size distributions and rheological properties of model oil-in-water emulsions. Innovative Food Science \& Emerging Technologies. 1:127-134.

[56] Jafari S.M., Assadpoora E., Heb Y. and Bhandari B. 2008. Re-coalescence of emulsion droplets during high-energy emulsification. Food Hydrocolloids. 22:1191-1202

[57]Floury J., Bellettre J., Legrand J. and Desrumaux A. 2004a. Analysis of a new type of high pressure homogenizer. A study of the flow pattern. Chemical Engineering Science. 59:843-853.

[58] Perrier-Cornet J. M., Marie P. and Gervais P. 2005. Comparison of emulsification efficiency of proteinstabilizedoil-in-water emulsions using jet, high pressure and colloid mill homogenization. Journal of Food Engineering. 66:211-217.

[59]Håkansson A., Tragårdh C. and Bergenståhl B. 2009b. Studying the effects of adsorption, recoalescence and fragmentation in a high pressure homogenizer using a dynamic simulation model. Food Hydrocolloids. 23:1177-1183
[60] Lee L., Hancocks R., Noble I.b. and Norton I.T. 2014. Production of water-in-oil nanoemulsions using high pressure homogenization: A study on droplet break-up. Journal of Food Engineering. 131:33-37.

[61] Jafari S. M., He Y. and Bhandari B. 2007a. Optimization of nano-emulsions production by microfluidization. Eur Food Res Technol. 225:733741.

[62] Stang M., Schuchmann H. and Schubert H. 2001. Emulsification in High-Pressure Homogenizers. Eng. Life Sci. 1(4):151-157.

[63] Gogate P.R. 2008. Cavitational reactors for process intensification of chemical processing applications: A critical review. Chemical Engineering and Processing. 47:515-527

[64] Patravale V.P., Date A.A. and Kulkarni R.M. 2004. Nanosuspension: a promising drug delivery strategy. Journal of Pharmacy and Pharmacology. 56:827840.

[65]Keck C. M. and Muller R. H. 2006. Drug nanocrystals of poorly soluble drugs produced by high pressure homogenization. European Journal of Pharmaceutics and Biopharmaceutics. 62:3-16.

[66] Gramdorf S., Hermann S., Hentshel A., Schrader K., Müller R. H. and Kraume M. 2008. Crystallized miniemulsions: Influence of operating parameters during high pressure homogenization on size and shape of particles. Colloids and Surfaces aPhysicochemical and Engineering Aspects. 331 (12):108-113.

[67] Cruz N., Capellas M., Hernandez M., Trujillo A.J., Guamis B. and Ferragut V. 2007. Ultra high pressure homogenization of soymilk: Microbiological, physicochemical and microstructural characteristics. Food Research International. 40:725-732.

[68] Suárez-Jacobo A., Rüfer C. Gervilla R. Guamis B., Roig-Sagués A. and Saldo J. 2011. Influence of ultra-high pressure homogenization on antioxidant capacity, polyphenol and vitamin content of clear apple juice. Food Chemistry. 127:447-454.

[69] Modigb, G., Lars-Nilssona, L., Bergensta B. and Wahlund, K. G. 2006. Homogenization-induced degradation of hydrophobically modified starch determined by asymmetrical flow field-flow fractionation and multi-angle light scattering. Food Hydrocolloids. 20:1087-1095.

[70] Nilsson, L. Leeman, M., Wahlund,K. G., and Bergenstahl, B. 2006. Mechanical Degradation and Changes in Conformation of hydrophobically Modified Starch. Biomacromolecules.7:2671-2679. 
[71] Wang, B., Wang, L., Li, D., Weia, Q. and Adhikaric, B. 2012. The rheological behavior of native and high-pressure homogenized waxy maize starch pastes. Carbohydrate Polymers. 88, 481489.

[72] Majzoobi M., Shahbazi M., Farahnaky A., Rezvani E. and Schleining G. 2013. Effects of high pressure homogenization on the physicochemical properties of corn starch. Inside Food Symposium, Leuven, Belgium.

[73] Augustin M.A., Sanguansri P. and Hotoon A. (2008). Functional performance of a resistant starch ingredient modified using a microfluidiser. Innovative Food Science and Emerging Technologies. 9:224-231.

[74]Floury J., Desrumaux A., Axelos M.A.V. and Legrand J. 2002. Degradation of methylcelluose during ultra-high pressure homogenization. Food Hydrocolloids. 16:47-53.

[75] Kasaai M.R., Charlet G., Paquin P. and Arul J. 2003. Fragmentation of chitosan by microfluidization process. Innovative Food Science and Emerging Technologies. 4: 403-413

[76] Schultz S., Wagner G., Urban K., and Ulrich J. 2004. High-pressure homogenization as a process for emulsion formation. Chem. Eng. Technol. 27(4):361-368.

[77] Nagasundara R.R., Ti T.B., Chuan L.T. and Ariff A.B. 2009. Classification of pressure range based on the characterization of Escherichia coli cell disruption in high pressure homogenizer. American Journal of Biochemistry and Biotechnology. 5(1):2129.

[78] Paquin P. 1999. Technological properties of high pressure homogenizers: the effect of fat globules, milk proteins and polysaccharides. Journal of Dairy Dcience. 9:329-335.

[79] Lacroix N., Fliss A. and Makhlouf J. 2005. Inactivation of pectin methylesterase and stabilization of opalescence in orange juice by dynamic high pressure. Food Research International. 38:569-576.

[80] Nogueira B.T., Bucco de Camposa V.E. Perdiz S.J., Cerqueira C.C. Santuzzi T.B., De Holanda S.K.G., Elias M.C.R. 2015. Development and characterization of promising $\mathrm{o} / \mathrm{w}$ nanoemulsions containing sweet fennel oil and non-ionic surfactants. Colloids and Surfaces A: Physicochemical and Engineering Aspects. 480:214221.

[81] Barenholz Y. and Lasic D.D. 1996. An overview of liposome scaled-up production and quality control, 23-30. In: Barenholz Y. and Lasic D.D. Handbook of nanomedical applications of liposomes. From design to microreactors. Volume III. CRC Press. Florida, USA.

[82] Kourniatis L. R., Spinelli L. S. and Mansur C. R. E. 2010. Formation of orange oil in water nanoemulsions using nonionic surfactants mixtures by high pressure homogenizer. Colloid Journal. 72 (3):396-402

[83] Yang X., Tian H., Ho C. and Huang Q. 2011. Inhibition of citral degradation by oil-in-water nanoemulsions combined with antioxidants. $J$. Agric. Food Chem. 59:6113-6119.

[84] Kim Y.D., Morr C.V. and Schenz T.W. 1996. Microencapsulation properties of gum Arabic and several food proteins: Liquid orange oil emulsion particles. J. Agric. Food Chem. 44:1308-1313.

[85] Bringas-Lantigua M., Valdés D. and Pino J.A. 2012. Influence of spray-dryer air temperatures on encapsulated lime essential oil. International Journal of Food Science and Technology. 47:15111517.

[86] Janiszewska E., Jedlinska A. and Witrowa-Rajchert D. 2015. Effect of homogenization parameters on selected physical properties of lemon aroma powder. Food and Bioproducts processing. 94:405-4013.

[87] Costa-García L., Valeriano-Tonton R. and DupasHubinger M. 2012. Effect of homogenization pressure and oil load on the emulsion properties and the oil retention of microencapsulated basil essential oil (Ocimum basilicum L.). Drying Technology: An international Journal. 30:1413-1421.

[88] Fichtali J. and Senanayake N. 2010. Development and commercialization of microalgae-based functional lipids, pp. 206-258. IN: Smith J and Charter E. Functional food product development. Wiley Blackwell. Singapore.

[89] Mirhosseini H., Ping-Tan C., Hamid N. S. A. and Yusof S. 2008. Effect of Arabic gum, xanthan gum and orange oil contents on $\zeta$-potential, conductivity, stability, size index and $\mathrm{pH}$ of orange beverage emulsion. Colloids and surfaces A: Physicochem. Eng. Aspects. 315:47-56.

[90] Hopkins T. R. 1991.Physical and Chemical cell disruption for the recovery of intracellular proteins, pp 57-86. In: Purification and Analysis of recombinant proteins. Seetharam R. and Sharma S. K. Marcel Deeker, Inc. New York

[91] Miettinen A. M., Tuorila H., Piironen V., Vehkalahtl K. and Hyvönen L. 2002. Effect of emulsion characteristics on the release of aroma as detected by senory evaluation, static headspace gas, chromatography and electronic nose. J. Agric. Food Chem. 50:4232-4239. 
[92] Dumbay E., Chevalier-Lucia D., Picart-Palmade L., Benzaria A. Gracia-Julia A. and Blayo C. 2013. Technological aspects and potential applications of (ultra) high-pressure homogenization. Trends in Food Science \& Technology. 31:13-26.

[93] Kaushik, V. and Roos, Y.H. 2007. Limonene encapsulation in freeze-drying of gum Arabicsucrose-gelatin systems. LWT - Food Sci. Tech. 40(8):1381-1391.

[94]Mullër R.H. and Junghanns J.A.H. 2006. Drug nanocrystals/nanosuspension for the delivery of poorly soluble drugs. In: Torchilin V. P. Nanoparticles as drugs carriers. Imperial College Pres. London.

[95] Thies C. 2012. Nanocapsules as delivery systems in the food, beverage and nutraceutical industries. 208250. In: Huang Q. Nanotechnology in the food, beverage and nutraceutical industries. Woodhead Publishing Series. UK.

[96] Guraya H.S. and James C. 2002. Deagglomeration of rice starch-protein aggregates by high-pressure homogenization. Starch/Stärke. 54:108-116.

[97]Zhang J. 2011. Novel emulsion-based delivery systems a submitted to the. Dissertation in partial fulfillment of the requirements for the degree of Doctor of Philosophy. Faculty of the graduate school of the University of Minnesota. USA.

[98] Monroy-Villagrana A., Cano-Sarmiento C., AlamillaBeltrán L., Hernández-Sánchez H. and GutiérrezLópez G.F. 2014. Coupled taguchi-RSM optimization of the conditions to emulsify $\alpha$-tocopherol in an Arabic gum-maltodextrins matrix by microfluidization. Revista Mexicana de Ingeniería Química. 13 (3):679-688.

[99]Rao J. and McClements D.J. 2011. Food grade microemulsions, nanoemulsions and emulsion: fabrication from sucrose monopalmitate \& lemon oil. Food Hydrocolloids. 25:1413-1423.

[100] Rao J. and McClements D.J. 2012. Impact of lemon oil composition on formation and stability of model food and beverage emulsions. Food Chemistry. 134:749-757.

[101] Rao J. and McClements D.J. 2012. Lemon oil solubilization in mixed surfactant solutions. Rationalizing microemulsions \& nanoemulsion formation. Food Hydrocolloids. 26:268-276

[102] Cho Y.H. and Park J. 2003. Evaluation of process parameters in the $\mathrm{O} / \mathrm{W} / \mathrm{O}$ multiple emulsion method for flavor encapsulation. Journal of Food Science. 68 (2):534-538.

[103] Lim S. S., Baik M.Y., Decker E.A., Henson L., Popplewell M., McClements D.J. and Choi S.J. 2011. Stabilization of orange oil-in-water emulsion:
A new role for ester gum as an Ostwal ripening inhibitor. Food Chemistry. 128:1023-1028.

[104] Soottitantawat A., Yoshii, H. Furuta T., Ohkawara M. and Linko P. 2003. Microencapulation by spray drying: influence of emulsion size on the retention of volatile compounds. Journal of Food Scince. 68(7):2255-2261.

[105] Soottitantawat A., Bigeard F., Yoshii H., Furuta T., Ohkawara M. and Linko P. 2005. Influence of emulsion and powder size on the stability of encapsulated d-limonene by spray drying. Innovative Food Science and Emerging Technologies. 6:107114.

[106] Donsi F., Annunziata M., Sessa M and Ferrari G. 2011. Nanoencapsulation of essential oils to enhance their antimicrobial activity in foods. LWT-Food Science and Technology. 44:1908-1914.

[107] Donsi F., Annunziata M., Vincensi M. and Ferrari G. 2012. Design of nanoemulsion-based delivery systems of natural antimicrobials: Effect of the emulsifier. Journal of Biotechnology. 159:342350 . 